
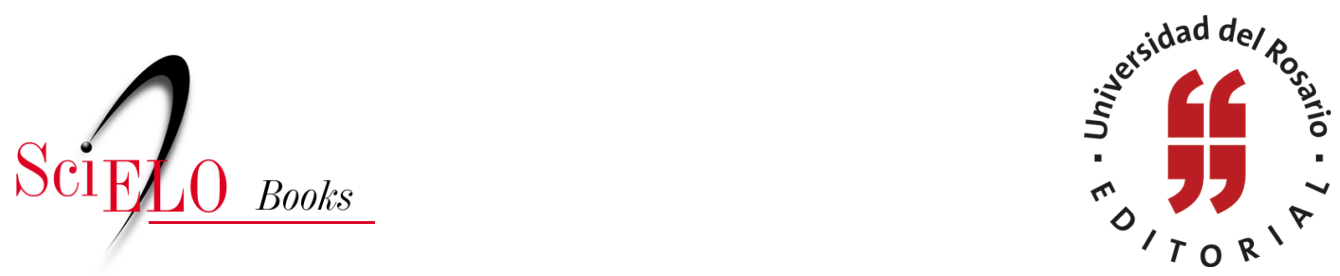

\title{
Conclusiones \\ Aportes para la agenda pendiente de la educación legal clínica y el litigio estratégico em Iberoamérica
}

\author{
Beatriz Londoño Toro
}

\section{SciELO Books / SciELO Livros / SciELO Libros}

LODOÑO TORO, B. Conclusiones. Aportes para la agenda pendiente de la educación legal clínica y el litigio estratégico em Iberoamérica. In: Educación legal clínica y litigio estratégico en Iberoamérica [online]. Bogotá: Editorial Universidad del Rosario, 2015, pp. 133-136. Textos de jurisprudencia collection. ISBN 978-958-738-624-0.

https://doi.org/10.7476/9789587386240.0004.

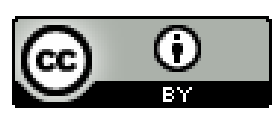

All the contents of this work, except where otherwise noted, is licensed under a Creative Commons Attribution 4.0 International license.

Todo o conteúdo deste trabalho, exceto quando houver ressalva, é publicado sob a licença Creative Commons Atribição 4.0.

Todo el contenido de esta obra, excepto donde se indique lo contrario, está bajo licencia de la licencia Creative Commons Reconocimento 4.0. 


\section{Conclusiones}

\section{Aportes para la agenda pendiente de la educación legal clínica y el litigio estratégico en Iberoamérica}

\section{Propuesta pedagógica}

Como hemos visto en este trabajo, la educación legal clínica puede ser una respuesta que complemente otras alternativas en la búsqueda de reformas a la educación jurídica en Iberoamérica.

Las clínicas tienen esa característica de nova et vetera tan importante en una propuesta de modelo pedagógico que, siendo innovador, hunde sus raíces en problemas que se han evidenciado en las facultades de derecho desde el siglo xix. Tienen además la característica esencial, acorde con los planeamientos de Bolonia, de ser una propuesta centrada en los estudiantes como eje constructor de cambios en la docencia, la investigación y la extensión universitaria. Reúne además elementos de fuentes teóricas muy valiosas, como el realismo jurídico y la teoría crítica, entre otras.

Conviene que a través de las redes de clínicas se busquen consensos sobre los principios pedagógicos y criterios que puedan identificar con claridad cuándo se está desarrollando verdadero trabajo clínico. Para la discusión proponemos los siguientes: (i) trabajo con un doble objetivo misional: intereses académicos e impacto social para solucionar problemas reales; (ii) responsabilidad de los estudiantes (son los líderes del proceso); (iii) cambio en el rol del profesor, pues asume el papel de supervisor, y (iv) trabajo en casos reales.

Se considera también importante que las clínicas tengan una norma interna de creación, un reglamento de acceso público y un rubro presupuestal.

Aún se evidencian muchas dificultades para la implementación de la educación legal clínica, entre ellas la tradición formalista de los sistemas jurídicos en la región y la falta de claridad sobre los presupuestos de funcionamiento de las clínicas. Se observa además que son escasos los escenarios de formación y sistematización de experiencias y, además, se carece de análisis regionales. 
Falta una revisión más profunda sobre la perspectiva pedagógica del trabajo de las clínicas. En América Latina, se debe avanzar en la consideración de que, más que un método, es un modelo en construcción. Algunas tareas adicionales pendientes se relacionan con la investigación y reflexión sobre los sistemas de evaluación en la educación legal clínica y con estrategias para lograr un enfoque multidisciplinario en el manejo de casos y en la investigación sobre educación jurídica.

La gran inquietud por el reconocimiento de las clínicas se orienta a que sean una práctica con valor académico, que los docentes sean de planta o de tiempo completo, que se valore en créditos la actividad de las clínicas y que se promueva institucionalmente su creación. Las clínicas deben relacionarse con las fortalezas académicas de las facultades y con su reconocimiento social y relaciones externas, ya que el litigio estratégico o el trabajo street law no puede hacerse sin alianzas.

Según el examen realizado a las clínicas iberoamericanas, se considera necesario fortalecer una inserción más clara de ellas en las facultades de derecho: hace falta una mayor visibilidad e inclusión curricular explícita. Se reconoce que existe una directa relación entre el fortalecimiento de la educación legal clínica y mayores y mejores estándares de calidad en la docencia jurídica; en los procesos de acreditación esta es una característica de gran importancia.

El rol de los docentes en este cambio es igualmente transformador e implica rupturas con paradigmas de docencia jurídica internalizados en las facultades durante varios siglos.

En la formación de docentes clínicos debe tenerse en cuenta que se requiere que existan profesionales interesados en desarrollar transformaciones en torno a la enseñanza del derecho y que sus esfuerzos generen el impacto suficiente. Se requiere en los docentes competencias específicas, experiencia en el área de trabajo de la clínica, habilidades didácticas — como el diseño de casos simulados (role playing) —, propuestas de atención de clientes, fortalezas en supervisión y revisión de escritos jurídicos, entre otras. Deben igualmente tener capacidad para generar procesos de autoaprendizaje y de aprendizaje activo y significativo con incidencia en la resolución de problemas relacionados con su entorno.

En relación con la estructura y funcionamiento de las clínicas, conviene revisar el compromiso institucional con esta figura y fortalecer los recursos físicos, el número de docentes supervisores, sus espacios de trabajo, el uso de 
nuevas tecnologías para apoyar el trabajo, y la divulgación en medios de comunicación, en internet y al interior de las universidades sobre el trabajo de las clínicas y su impacto social y académico.

Tal vez la mayor complejidad del modelo está en su insumo central: los casos reales, el acercamiento del estudiante a su entorno, el aprendizaje para asumir problemas y buscar soluciones integrando conocimientos y saberes de su profesión. Tiene además un don maravilloso y es que atrae poderosamente a los estudiantes, pues el nuevo rol que asumen los dignifica; pasan de ser simples depositarios de saberes ajenos a constructores de su propio conocimiento, con un acompañamiento especializado y personal de los docentes supervisores de la clínica.

Es igualmente necesario reconocer que el antecesor más importante de la educación legal clínica han sido los denominados servicios legales gratuitos, bufetes o consultorios jurídicos, que han existido desde los años sesenta en la mayoría de los países iberoamericanos, salvo en el caso de España.

La propuesta es asumir las clínicas como una evolución de los servicios ya existentes y permitir que continúe la atención para el acceso a la justicia individual que se viene prestando de forma eficiente en la región, pero que se complemente con las clínicas como servicios de acceso colectivo o individual en casos de interés público, derechos humanos y otras áreas del derecho.

Esta visión de complementariedad y no de oposición entre modelos permitiría el fortalecimiento de las prácticas jurídicas, la formación de los estudiantes en responsabilidad social universitaria y el acceso a la justicia gratuita y de calidad para quienes lo requieran.

En el rediseño curricular, conviene igualmente que esta evolución sea explícita y que se asignen créditos a las prácticas en consultorio jurídico o en clínicas jurídicas. Los impactos de estos cambios en la educación jurídica serán visibles en el fortalecimiento de competencias específicas en materia de investigación, ejercicio directo del derecho y aprendizaje de valores éticos y ciudadanos. De igual forma, la repercusión social y la visibilidad de estos servicios de extensión por parte de las universidades permitirán más altos estándares en los resultados de extensión, aprendizaje-servicio y responsabilidad social universitaria, y esto se reflejará en los procesos de acreditación.

Se considera que un concepto medular del trabajo clínico en Iberoamérica ha sido el litigio estratégico, y que los cambios estructurales se dan a largo 
plazo y requieren del acompañamiento de las organizaciones y las universidades a través de la acción y la investigación.

Surge como un elemento de consenso la importancia del trabajo en redes y comunidades de práctica en el que se profundicen experiencias, formas de trabajo y sistemas de evaluación. Otras recomendaciones importantes apuntan a fortalecer el intercambio de docentes, apoyar ejercicios de supervisión, realizar propuestas de trabajo en grupos o inter-clínicas para casos complejos, hacer reuniones temáticas, fortalecer los sitios web en los que esté la información de apoyo a las clínicas, videoconferencia con los estudiantes de otras clínicas y, en general, la promoción de estrategias de enlace y relacionamiento.

El enfoque temático se impone en el diseño de las nuevas clínicas y en la selección de los casos. Esta evolución que parte de las fortalezas de las universidades y las organizaciones permite la sostenibilidad de las clínicas y garantiza procesos de aprendizaje e investigación con resultados claros que se pueden sistematizar. De igual forma facilita la construcción y permanencia de las redes y las alianzas con ONG, organizaciones pro bono y otras clínicas o instituciones nacionales o internacionales en torno a objetivos comunes.

La definición de las temáticas a abordar por las clínicas implica trabajo previo de investigación, examen de la situación de derechos humanos y de los problemas más significativos a los cuales se trata de dar una respuesta desde las universidades, con un carácter realista e innovador.

Es igualmente importante conocer y multiplicar en Iberoamérica las experiencias que se tienen en clínicas de maestría. Son ejemplos importantes los trabajos de las universidades de Palermo (en Argentina), Carlos III, Valencia, Barcelona y Tarragona (en España). Los estudiantes de posgrado pueden aportar valiosos conocimientos y un tratamiento profundo y cualificado a la labor de litigio estratégico en todas sus modalidades. 